\title{
Retropubic, Laparoscopic, and Robot-Assisted Radical Prostatectomy: A Critical Review of Outcomes Reported by High-Volume Centers
}

\author{
Rafael F. Coelho, M.D., ${ }^{1,2}$ Bernardo Rocco, M.D., ${ }^{1,3}$ Manoj B. Patel, M.D., Marcelo A. Orvieto, M.D., \\ Sanket Chauhan, M.D., Vincenzo Ficarra, M.D., ${ }^{4}$ Sara Melegari, M.D., ${ }^{3}$ \\ Kenneth J. Palmer, M.D., ${ }^{1}$ and Vipul R. Patel, M.D.1
}

\begin{abstract}
Purpose: To critically review perioperative outcomes, positive surgical margin (PSM) rates, and functional outcomes of several large series of retropubic radical prostatectomy (RRP), laparoscopic RP (LRP), and robotassisted radical prostatectomy (RARP) currently available in the literature.

Methods: A Medline database search was performed from November 1994 to May 2009, using medical subject heading search terms "prostatectomy" and "Outcome Assessment (Health Care)" and text words "retropubic," "robotic," and "laparoscopic." Only studies with a sample size of 250 or more patients were considered. Weighted means were calculated for all outcomes using the number of patients included in each study as the weighing factor.

Results: We identified 30 articles for RRP, 14 for LRP, and 14 for RARP. The mean intraoperative and postoperative RRP transfusion rates for RRP, LRP, and RARP were $20.1 \%, 3.5 \%$, and $1.4 \%$, respectively. The weighted mean postoperative complication rates for RRP, LRP, and RARP were $10.3 \%$ (4.8\% to $26.9 \%), 10.98 \%$ ( 8.9 to $27.7 \%$ ), and $10.3 \%$ (4.3\% to $15.7 \%$ ), respectively. RARP revealed a mean overall PSM rate of $13.6 \%$, whereas LRP and RRP yielded a PSM of $21.3 \%$ and $24 \%$, respectively. The weighted mean continence rates at 12 month follow-up for RRP, LRP, and RARP were $79 \%, 84.8 \%$, and $92 \%$, respectively. The weighted mean potency rates for patients who underwent unilateral or bilateral nerve sparing, at 12 month follow-up, were $43.1 \%$ and $60.6 \%$ for RRP, $31.1 \%$ and $54 \%$ for LRP, and $59.9 \%$ and $93.5 \%$ for RARP.

Conclusion: RRP, LRP, and RARP performed in high-volume centers are safe options for treatment of patients with localized prostate cancer, presenting similar overall complication rates. LRP and RARP, however, are associated with decreased operative blood loss and decreased risk of transfusion when compared with RRP. Our analysis including high-volume centers also showed lower weighted mean PSM rates and higher continence and potency rates after RARP compared with RRP and LRP. However, the lack of randomized trials precludes definitive conclusions.
\end{abstract}

\section{Introduction}

$\mathbf{P}$ ROSTATE CANCER IS THE MOST commonly diagnosed nonskin cancer and the second leading cause of cancerrelated death in men in the United States. ${ }^{1,2}$ The incidence of prostate cancer rose dramatically in the late 1980s, reflecting improvements in detection through the widespread use of prostate-specific antigen (PSA) testing. ${ }^{2}$ As a result, prostate cancer is now a frequent diagnosis in younger and healthier men, with organ-confined disease, who desire to undergo definitive treatment, while maintaining their current quality of life. Because a myriad of treatment options is currently available, however, decision making for the patient can be confusing and stressful. Even among surgical options, the patient needs to decide whether to have open, laparoscopic or robot-assisted surgery.

Since Walsh and Donker ${ }^{3}$ first introduced the anatomic nerve-sparing technique for retropubic radical prostatectomy (RRP), it has become the gold standard and most widespread treatment for patients with clinically localized

\footnotetext{
${ }^{1}$ Global Robotics Institute, Florida Hospital Celebration Health, Celebration, Florida; University of Central Florida School of Medicine, Orlando, Florida.

${ }^{2}$ Divisão de Urologia, Hospital das Clinicas da Faculdade de Medicina da Universidade de São Paulo, São Paulo, Brazil.

${ }^{3}$ European Institute of Oncology, Milan, Italy.

${ }^{4}$ Department of Oncological and Surgical Sciences, Urology Clinic, University of Padua, Padua, Italy.
} 
prostate cancer, providing excellent cancer control in most patients with clinically localized disease. ${ }^{4-6}$ In an effort to further decrease the morbidity of RRP, a minimally invasive surgical approach to managing prostate cancer was first described by Schuessler and colleagues ${ }^{7}$ in 1992 . The initial experience with laparoscopic radical prostatectomy (LRP), however, was discouraging, and the authors concluded that the procedure was extremely difficult, associated with a steep learning curve, and offered no advantages over RRP. Subsequently, larger LRP series were reported showing feasibility of the procedure and results comparable to those of the open surgical approach. ${ }^{8-10}$ Despite this, the technical demands of the surgery and the protracted learning curve have prevented the widespread adoption of LRP by most urologic surgeons.

The introduction of the da Vinci Robotic Surgical System (Intuitive Surgical, Inc., Sunnyvale, CA) has been a key step toward a minimally invasive approach to radical prostatectomy (RP) because of its technologic peculiarities, such as three-dimensional vision, seven degrees of freedom, and magnification. Almost one decade after the introduction of robot-assisted radical prostatectomy (RARP) ${ }^{11,12}$ and several modifications to the original surgical technique, the procedure is currently standardized. More importantly, the data from large series are now mature enough to be critically compared with other large RRP and LRP series.

The aim of our study was to critically review perioperative outcomes, positive surgical margin (PSM) rates, and functional outcomes of the largest RRP, LRP, and RARP series currently available in the literature.

\section{Method}

A Medline database search was performed from November 1994 to May 2009, using medical subject heading search terms "prostatectomy" and "Outcome Assessment (Health Care)" and text words "retropubic," "robotic," and "laparoscopic." Additional hand searches based on references from relevant review articles were also performed. ${ }^{13-15}$ Only studies that were published in the English language and with a sample size of 250 or more patients were considered. Studies with a total sample size larger than 250 patients but with fewer patients specifically evaluated for continence or potency rates were also included in the analysis. Comparative studies were also included in the analysis and data from each group were pooled according to the surgical approach. No data from abstracts or reports from meetings were included in the review.

End points evaluated included perioperative outcomes (operative time, blood loss, transfusion rate, hospital stay, catheter time, and overall complication rates); functional outcomes (urinary continence, potency recovery); and PSM rates. Weighted means were calculated for all outcomes using the number of patients included in each study as the weighting factor.

\section{Results}

We identified 30 articles for RP, 14 for LRP, and 14 for RARP. The distribution of published articles over the years is shown in Figure 1. The weighted mean patient age for RRP, LRP, and RARP series included in the studies was 61.3 years (range of means, 58-65 years), 62.9 years (range of means,

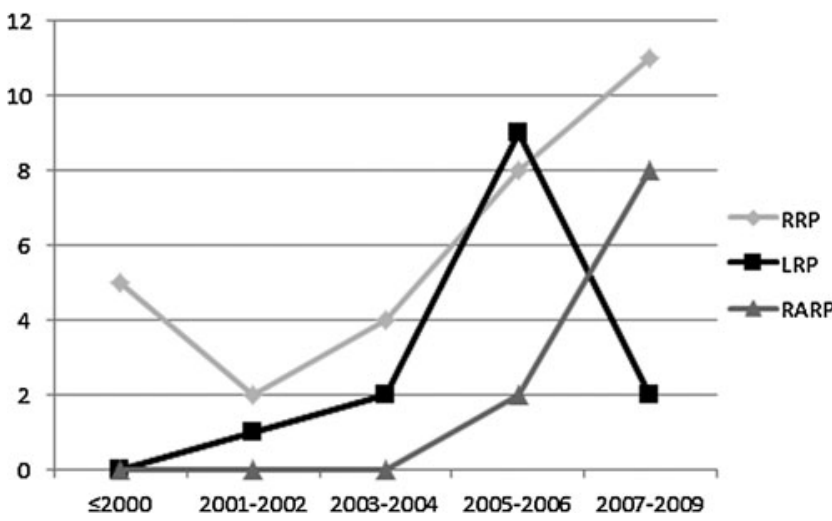

FIG. 1. Distribution of articles published by high-volume centers ( $>250$ patients).

57.6-64 years) and 60.4 years (range of means, 59.2-63.5 years), respectively.

\section{Perioperative outcomes}

The results for operative time, blood loss, blood transfusion rates, hospital stay, and overall complication rates for RARP, LRP, and RRP are presented on Table $1,^{16-36}$, Table $2,^{33,37-47}$ and Table $3{ }^{28,30,31,43,48-54}$ respectively.

The weighted means for operative time were 165 minutes (range 131-204 $\mathrm{min}$ ) for RRP, 162.6 minutes (130-236 $\mathrm{min}$ ) for the RARP series, and 205 minutes (100-266 min) for the LRP series. The mean estimated blood loss (EBL) for RRP, LRP, and RARP was $951 \mathrm{~mL}, 291.5 \mathrm{~mL}$, and $164.2 \mathrm{~mL}$, respectively. The mean intraoperative and postoperative RRP transfusion rates for RRP, LRP, and RARP were $20.1 \%, 3.5 \%$, and $1.4 \%$, respectively.

In terms of hospital stay, RP series account for a weighted mean of 3.48 days; the mean hospital stay for LRP and RARP was 4.87 and 1.43 days, respectively.

The weighted mean postoperative complication rates for RRP, RLP, and RARP were $10.3 \%$ (range of means $4.8 \%$ $26.9 \%$ ), $10.98 \%$ (range of means $8.9 \%-27.7 \%$ ), and $10.3 \%$ (range of means $4.3 \%-15.7 \%$ ), respectively.

Some RARP cases needed conversion to laparoscopy or RRP, and some of the RLP cases were converted to open surgery. The mean open conversion rate for RARP was $0.34 \%$ (range of means $0 \%-1.6 \%$ ) and for LRP was $1.76 \%$ (range of means $0 \%-2.4 \%$ ).

\section{Oncologic outcomes}

The pathologic stage and PSM rates for open, RLP, and RARP series are summarized on Table $4,16-22,24-28,30,31,33,55-57$ Table 5, ${ }^{33,37,38,40-42,44-47}$ and Table $6,^{30,31,35,48-54,58}$ respectively.

The pathologic stage in the RARP series was of $78.2 \% \mathrm{pT}_{2}$ tumors and $20.5 \% \mathrm{pT}_{3}$ tumors. LRPs were performed on $64 \%$ $\mathrm{pT}_{2}$ and $32.6 \% \mathrm{pT}_{3}$ tumors, and RRPs on $64.3 \% \mathrm{pT}_{2}$ and $31.5 \%$ $\mathrm{pT}_{3}$ tumors. RARP revealed a mean overall PSM rate of $13.6 \%$, whereas LRP and RRP yielded a PSM of $21.3 \%$ and $24 \%$, respectively. The mean $\mathrm{PSM}_{\text {rate for }} \mathrm{pT}_{2}$ and $\mathrm{pT}_{3}$ tumors in the RARP series was $9.6 \%$ and $37.1 \%$, respectively; in the open series, it was $16.8 \%$ and $42 \%$, respectively; and in the LRP series, it was $12.4 \%$ and $39.2 \%$, respectively. 


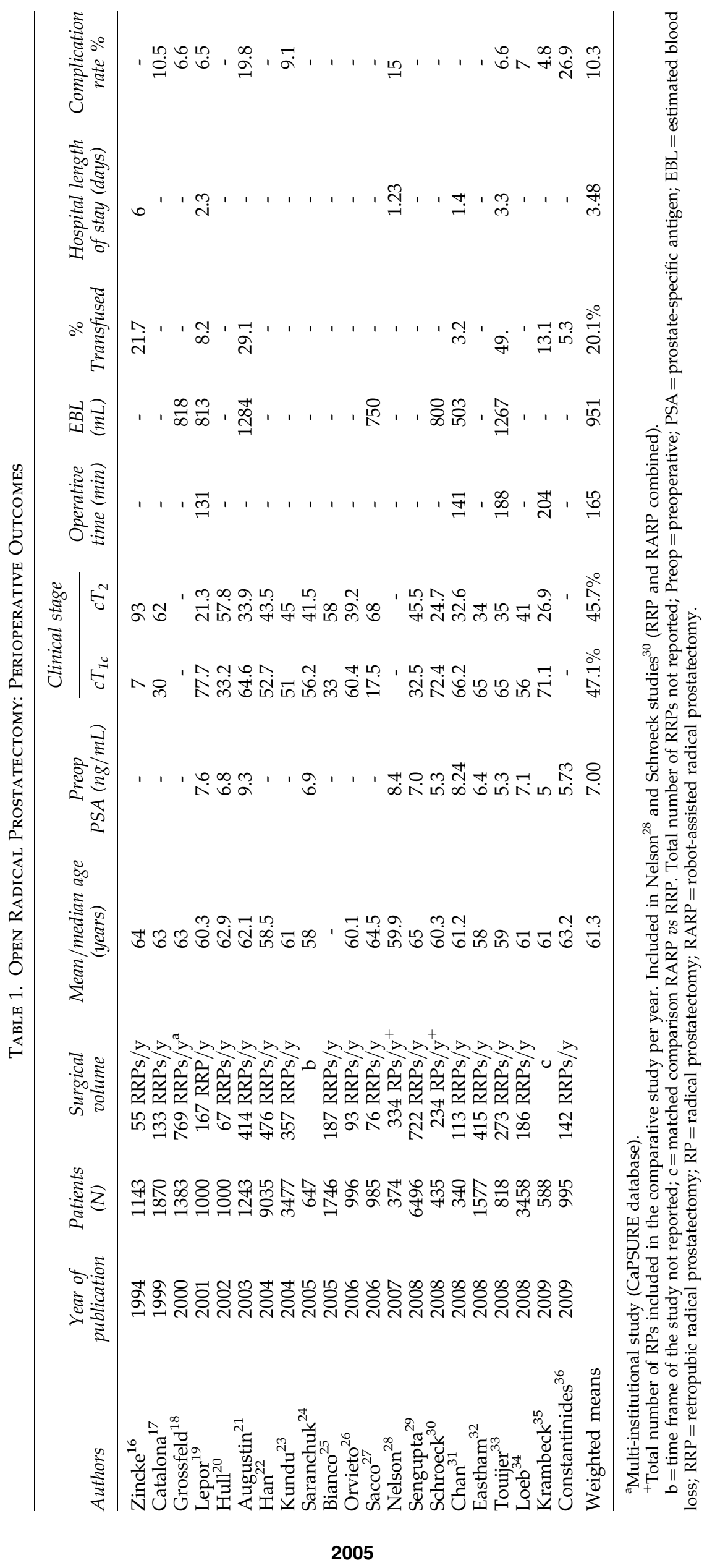




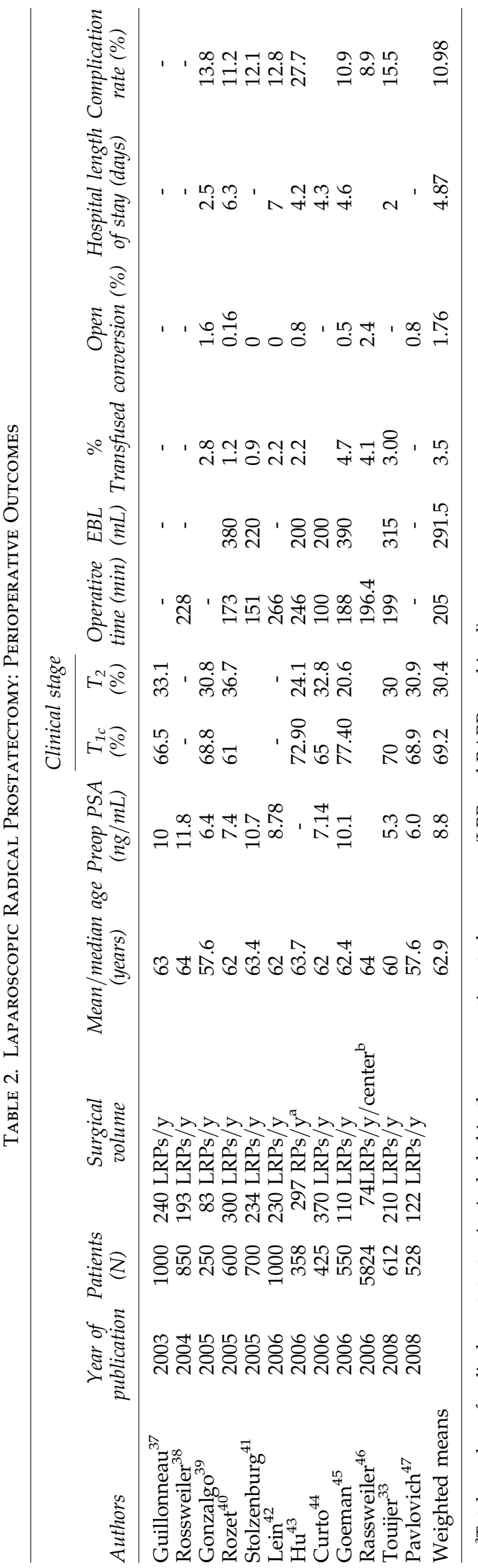

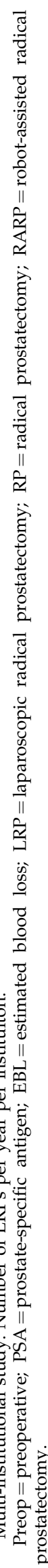

\section{Urinary continence outcomes}

Postoperative urinary continence outcomes for RARP, LRP, and RRP are tabulated in Table $7,16,17,23-25,27,32-35,59-61$ Table $8,^{38,40-42,44-46,62}$ and Table 9. . $^{35,48,50,51,53,58,63,64}$

Direct comparisons for urinary continence rates between different prostatectomy series are difficult because of variations in definitions, data collection methods, and length of follow-up. In this review, the definition of continence that was adopted to collect the data from the studies was the use of no absorbent pads or the use of one pad only for security. We identified $14 \mathrm{RRP}, 9 \mathrm{LRP}$, and 8 RARP studies with more than 250 patients and a follow-up longer than 6 months. The RRP continence rates ranged from $33.7 \%$ to $68 \%, 38.6 \%$ to $78 \%$, $60.5 \%$ to $93.7 \%$, and 58.1 to $96 \%$ at $3,6,12$, and 18 months of follow-up, respectively. The LRP continence rates ranged from $51 \%$ to $76 \%, 70 \%$ to $95 \%, 82.3 \%$ to $95 \%$, and 62.1 to $97 \%$ at $3,6,12$, and 18 months of follow-up, respectively. Reports for RARP revealed continence rates of $47 \%$ to $93 \%, 61.9 \%$ to $97 \%$, and $82.1 \%$ to $97 \%$ at 3, 6, and 12 months of follow-up, respectively. The weighted mean continence rates at 12 months of follow-up for RRP, LRP, and RARP were 79\%, $84.8 \%$, and $92 \%$, respectively.

\section{Potency outcomes}

The potency rates for RRP, LRP, and RARP are detailed on Table $10^{17,23,24,32-34,59,60,65-68}$ Table $11,33,38,40,41,44-46,62,69$ and Table 12. ${ }^{35,48,51,53,63,64}$ As for continence, comparisons of the potency rates between different series are extremely difficult. Several ways to assess postoperative potency are used, including different questionnaires (International Index of Erectile Function, Expanded Prostate Cancer Index Composite) and distinct methods of data gathering (telephone, personal interviews, etc). The type of nerve-sparing procedure (unilateral, bilateral, nonnerve-sparing) and the use of medications can also influence the outcomes, in addition to the surgical approach adopted.

We identified 13 RRP, 9 LRP, and 6 RARP studies with more than 250 patients and with reported potency rates beyond 1 year. Evaluating RRP, the weighted mean potency rates for patients who underwent unilateral or bilateral nerve sparing, at 12 months of follow-up, were $43.1 \%$ and $60.6 \%$, respectively. The LRP weighted mean potency rates for patients who received unilateral and bilateral nerve-sparing procedures, at 12 months of follow-up, were $31.1 \%$ and $54 \%$, respectively; Finally, RARP patients who received unilateral and bilateral nerve-sparing procedures had potency rates, at 12 months of follow-up, of $59.9 \%$ and $93.5 \%$, respectively.

\section{Discussion}

There are some clear problems with comparing open RP vs LRP vs RARP for the treatment of patients with organconfined prostate cancer: There are no randomized studies that compare the three surgical approaches; definitions used to describe positive margins, biochemical recurrence, urinary continence, and sexual function are not standardized and may differ significantly between series; finally, centers where RARP is performed are usually focused only in this approach, limiting their practice with open or laparoscopic procedures. Consequently, comparative randomized studies that evaluate 


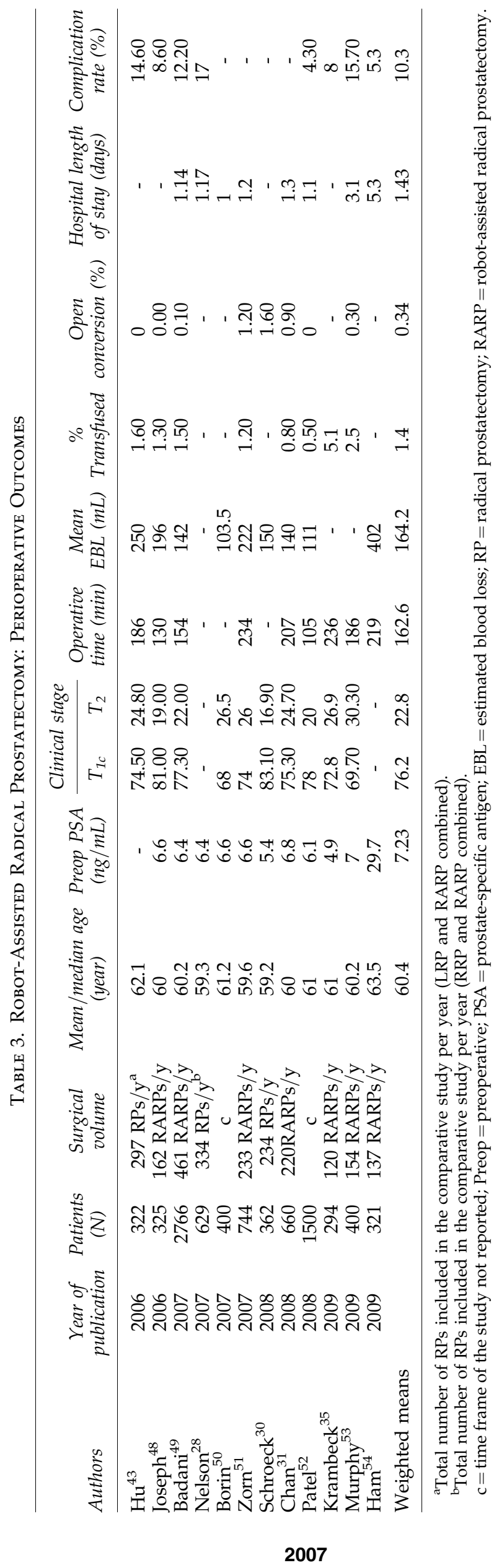


Table 4. Open Radical Prostatectomy: Oncologic Outcomes

\begin{tabular}{|c|c|c|c|c|c|c|c|c|}
\hline \multirow[b]{2}{*}{ Authors } & \multirow{2}{*}{$\begin{array}{l}\text { Year of } \\
\text { publication }\end{array}$} & \multirow[b]{2}{*}{ Patients (N) } & \multicolumn{3}{|c|}{ Pathologic staging } & \multicolumn{3}{|c|}{ Positive surgical margins } \\
\hline & & & $p T_{2}(\%)$ & $p T_{3}(\%)$ & $p T_{4}(\%)$ & $p T_{2}(\%)$ & $p T_{3}(\%)$ & Overall (\%) \\
\hline Zincke $^{16}$ & 1994 & 1143 & 53.2 & 34.7 & - & - & - & 12 \\
\hline Grossfeld $^{18}$ & 2000 & 1383 & 74.5 & \multicolumn{2}{|c|}{$25.5\left(\mathrm{pT}_{3}+\mathrm{pT}_{4}\right)$} & 26 & $\begin{array}{l}- \\
-67.3\end{array}$ & 34 \\
\hline Lepor $^{19}$ & 2001 & 1000 & 76.6 & 21.6 & 1.5 & - & - & 19.9 \\
\hline Hull $^{20}$ & 2002 & 1000 & 59.5 & 33.3 & - & - & - & 12.8 \\
\hline Augustin ${ }^{21}$ & 2003 & 1243 & 67 & 31.3 & 1.4 & - & & 21.4 \\
\hline Ward $^{55}$ & 2004 & 7268 & 69 & 31 & - & 28 & 58 (+EPE) & 38 \\
\hline $\mathrm{Han}^{22}$ & 2004 & 9035 & 58.2 & 38.3 & - & 7.7 & 26.9 & 14.7 \\
\hline Saranchuk ${ }^{24}$ & 2005 & 647 & 76.5 & 21.5 & 1.9 & - & - & 13 \\
\hline Bianco $^{25}$ & 2005 & 1746 & 66 & & - & - & - & 12 \\
\hline Orvieto $^{26}$ & 2006 & 996 & 69.7 & 30.1 & - & 1.7 & 24.9 & 8.8 \\
\hline Porter $^{56}$ & 2006 & 752 & 54.6 & 37.6 & - & - & \multirow{2}{*}{$\begin{array}{l}- \\
-\end{array}$} & 37.6 \\
\hline $\mathrm{Sacco}^{27}$ & 2006 & 985 & 57.1 & - & - & - & & 13.7 \\
\hline Chun $^{57}$ & 2006 & 4277 & 64.4 & - & - & - & - & 21.5 \\
\hline Sengupta ${ }^{29}$ & 2008 & 6496 & 69.1 & \multicolumn{2}{|c|}{$25.7\left(\mathrm{pT}_{3}+\mathrm{pT}_{4}\right)$} & - & - & 38.2 \\
\hline Schroeck $^{30}$ & 2008 & 435 & 74.5 & \multicolumn{2}{|c|}{$25.5\left(\mathrm{pT}_{3}+\mathrm{pT}_{4}\right)$} & - & \multirow{2}{*}{ - 56.7} & 28 \\
\hline Chan $^{31}$ & 2008 & 340 & 66.4 & 33.1 & 0.5 & 22.5 & & 34 \\
\hline Eastham $^{32}$ & 2008 & 1577 & 71 & $\begin{array}{c}28 \text { EPE } \\
6 \text { SVI }\end{array}$ & - & - & - & 11 \\
\hline Touijer $^{33}$ & 2008 & 818 & - & $\begin{array}{c}32 \mathrm{EPE} \\
6 \mathrm{SVI}\end{array}$ & - & - & - & 11 \\
\hline Krambeck $^{35}$ & 2009 & 588 & 88.6 & \multicolumn{2}{|c|}{$10.1 \%\left(\mathrm{pT}_{3}+\mathrm{pT}_{4}\right)$} & - & - & 17 \\
\hline Weighted means & & & 64.3 & 31.5 & 1.54 & 16.8 & 42 & 24 \\
\hline
\end{tabular}

$\mathrm{EPE}=$ extraprostatic extension; $\mathrm{SVI}=$ seminal vesicle invasion

the three approaches in the same institution are scarce and include small patient series, which represent the surgeons' learning curve. ${ }^{13,70}$

Recently, two systematic reviews and meta-analysis of the literature evaluated the results of LRP, RARP, and RRP. Parsons and Bennett ${ }^{14}$ conducted a meta-analysis of 19 observational studies that compared either laparoscopic or robotic-assisted with retropubic prostatectomy. Ficarra and associates $^{13}$ subsequently evaluated the perioperative, functional, and oncologic results in 37 comparative studies (RRP to LRP, RRP to RARP, or LRP to RARP). Both reviews demonstrated significantly lower blood loss and transfusion rates for LRP and RARP series compared with open RRP. None of the studies was able to prove the advantage of any surgical approach in terms of functional and oncologic outcomes. However, as expected in a meta-analysis, these two studies evaluated case series or cohorts that directly compared the surgical approaches within the same study. Consequently, some of the largest noncomparative cohorts carried out by experienced surgeons were not included in the statistical analysis.

In our review, we evaluated only the largest series (more than 250 patients) published with the three surgical approaches. Our aim was to analyze the outcomes of highvolume centers, minimizing the potential bias of the initial learning curve for each procedure.

Table 5. Laparoscopic Radical Prostatectomy: Oncologic Outcomes

\begin{tabular}{|c|c|c|c|c|c|c|c|c|}
\hline \multirow[b]{2}{*}{ Authors } & \multirow[b]{2}{*}{ Year of publication } & \multirow[b]{2}{*}{ Patients (N) } & \multicolumn{3}{|c|}{ Pathologic staging } & \multicolumn{3}{|c|}{ Positive surgical margins } \\
\hline & & & $p T_{2}(\%)$ & $p T_{3}(\%)$ & $p T_{4}(\%)$ & $p T_{2}(\%)$ & $p T_{3}(\%)$ & Overall (\%) \\
\hline Guillonneau $^{37}$ & 2003 & 1000 & 77.5 & 21.9 & - & 15.5 & 31.1 & 19.2 \\
\hline Rossweiler ${ }^{38}$ & 2004 & 850 & 58.4 & 36.5 & 3.7 & 7.08 & 38.6 & 22 \\
\hline Rozet $^{40}$ & 2005 & 600 & 72 & 28 & - & 14.6 & 26.2 & 17.8 \\
\hline Stolzenburg $^{41}$ & 2005 & 700 & 55.4 & 43.9 & 0.6 & 10.8 & 31.2 & 19.7 \\
\hline Lein $^{42}$ & 2006 & 1000 & 70.2 & 29.4 & 0.4 & 15 & 54.6 & 27 \\
\hline Curto $^{43}$ & 2006 & 425 & 58.5 & 41.3 & - & 21.9 & 43.3 & 30.7 \\
\hline Rassweiler ${ }^{44}$ & 2006 & 5824 & 60.7 & 36.7 & 1.9 & 10.6 & 39.4 & 21.2 \\
\hline Goeman $^{45}$ & 2006 & 550 & 55.8 & 38.7 & 5.4 & 17.9 & 44.8 & 31.3 \\
\hline Pavlovich $^{47}$ & 2008 & 528 & 81.5 & 17.5 & - & 8.2 & 39.9 & 13.7 \\
\hline Touijer $^{33}$ & 2008 & 612 & - & $\begin{array}{c}26 \text { EPE } \\
4 \text { SVI }\end{array}$ & - & - & - & 11 \\
\hline Weighted means & - & - & 64 & 32.6 & 3.6 & 12.4 & 39.2 & 21.3 \\
\hline
\end{tabular}

$\mathrm{EPE}=$ extraprostatic extension; $\mathrm{SVI}=$ seminal vesicle invasion. 
Table 6. Robot-Assisted Radical Prostatectomy: Oncologic Outcomes

\begin{tabular}{|c|c|c|c|c|c|c|c|c|}
\hline \multirow[b]{2}{*}{ Authors } & \multirow[b]{2}{*}{ Year of Publication } & \multirow[b]{2}{*}{ Patients (N) } & \multicolumn{3}{|c|}{ Pathologic staging } & \multicolumn{3}{|c|}{ Positive surgical margins } \\
\hline & & & $p T_{2}(\%)$ & $p T_{3}(\%)$ & $p T_{4}(\%)$ & $p T_{2}(\%)$ & $p T_{3}(\%)$ & Overall (\%) \\
\hline Joseph $^{48}$ & 2006 & 325 & 81.00 & 19.00 & - & - & - & 13.00 \\
\hline Badani $^{49}$ & 2007 & 2766 & 77.70 & 22.00 & 0.30 & 13.00 & 35.00 & 12.30 \\
\hline Zorn $^{51}$ & 2007 & 744 & - & - & - & 12.90 & 44.80 & 18.80 \\
\hline Borin $^{52}$ & 2007 & 400 & 73.5 & $26.5(\mathrm{p}$ & $\left.{ }_{3}+\mathrm{pT}_{4}\right)$ & 6.1 & 31.9 & 12.5 \\
\hline Tewari $^{58}$ & 2008 & 700 & 83.5 & 13.6 & 2.9 & 5.4 & - & - \\
\hline Schroeck $^{30}$ & 2008 & 362 & 79.30 & 20.70 & 0 & - & - & 29.30 \\
\hline Chan $^{31}$ & 2008 & 660 & 80.60 & 19.40 & 0 & 11.30 & 45.00 & 17.90 \\
\hline Patel $^{52}$ & 2008 & 1500 & 78.30 & 19.50 & 1.50 & 4.00 & 34.00 & 9.30 \\
\hline Murphy $^{53}$ & 2009 & 400 & 70 & 29.80 & 0.20 & 9.60 & 42.30 & 19.20 \\
\hline Krambeck $^{35}$ & 2009 & 294 & 90.1 & $9.9(\mathrm{p})$ & $\left.+\mathrm{pT}_{4}\right)$ & - & - & 15.6 \\
\hline $\mathrm{Ham}^{54}$ & 2009 & 321 & 55.1 & $43.7^{1}$ & 1.2 & - & - & 33.3 \\
\hline Weighted means & & & 78.7 & 20.5 & 0.8 & 9.6 & 37.1 & 13.6 \\
\hline
\end{tabular}

\section{Perioperative outcomes}

It is difficult to compare operative times between different series because of variations in reporting operative time (including or not setup and/or pelvic lymph node dissection). In our study, the weighted mean operative times for RRP and RARP were similar (165 and $162.6 \mathrm{~min}$, respectively). The weighted mean operative time $(205 \mathrm{~min})$ was longer in those patients who were undergoing LRP compared with the other two approaches. Similarly, the systematic review conducted recently by Ficarra and colleagues ${ }^{13}$ suggested that RARP is more time consuming than RRP only in the earlier phase of the learning curve $\mathrm{e}^{71}$ but that such differences disappeared with increased surgical experience. The same meta-analysis also showed that the operative time is significantly longer in those patients who are undergoing LRP compared with RRP.

Badani and colleagues ${ }^{49}$ recently reported their experience after 2766 RARPs. For the entire cohort, the mean surgical time (calculated from the time of Veress needle placement to skin closure) and the mean console time was 154 minutes and 116 minutes, respectively. They compared the results of their first 200 patients (group 1) with their last 200 patients (group 2). For group 1, the mean surgical and console times were 160 minutes and 121 minutes, respectively; for group 2, the mean surgical and console times were 131 minutes and 97 minutes, respectively. The robotic setup and docking time also decreased from 45 minutes in group 1 to 8 minutes in group 2.

Decreased intraoperative blood loss has been reported to be a hallmark advantage of laparoscopic/robot-assisted prostatectomy. Because most intraoperative blood loss originates from the venous sinuses, the tamponade effect created by pneumoperitoneum helps to diminish blood loss. In addition, early identification and precise ligation of vessels facilitate the limitation of blood loss. In our study, the weighted mean EBL and the mean intraoperative and postoperative RRP transfusion rates were also higher for RRP than LRP and RARP (mean EBL $951 \mathrm{~mL}$ vs $291.5 \mathrm{~mL}$ vs $164.2 \mathrm{~mL}$, respectively; transfusion rates $23 \%, 3.5 \%$, and $1.4 \%$, respectively). Two recent meta-analyses of studies that directly compared RRP, LRP, and RARP confirmed that RARP is associated with decreased operative blood loss and decreased risk of transfusion

Table 7. Open Radical Prostatectomy: Urinary Continence Outcomes

\begin{tabular}{|c|c|c|c|c|c|c|c|c|c|}
\hline \multirow[b]{2}{*}{ Authors } & \multirow[b]{2}{*}{$\begin{array}{c}\text { Year of } \\
\text { publication }\end{array}$} & \multirow[b]{2}{*}{$\begin{array}{l}\text { Patients } \\
(N)\end{array}$} & \multirow[b]{2}{*}{$\begin{array}{c}\text { Mean/median age } \\
\text { (years) }\end{array}$} & \multirow[b]{2}{*}{$\begin{array}{c}\text { Mean/median } \\
\text { follow-up (months) }\end{array}$} & \multicolumn{5}{|c|}{$\%$ Urinary continence } \\
\hline & & & & & $\begin{array}{c}1 \\
\text { month }\end{array}$ & $\begin{array}{c}3 \\
\text { months }\end{array}$ & $\begin{array}{c}6 \\
\text { months }\end{array}$ & $\begin{array}{c}12 \\
\text { months }\end{array}$ & $\begin{array}{l}>18 \\
\text { months }\end{array}$ \\
\hline Zincke $^{16}$ & 1994 & 1000 & 64 & 12 & - & - & - & 78.8 & - \\
\hline Catalona $^{17}$ & 1999 & 1325 & 63 & 18 & - & - & - & - & 92 \\
\hline $\mathrm{Kao}^{59}$ & 2000 & 1069 & 63.6 & $>6$ & - & - & 67 & - & - \\
\hline Stanford ${ }^{60}$ & 2000 & 1291 & 62.9 & $>18$ & - & - & 38.6 & 60.5 & 58.1 \\
\hline Lepor $^{61}$ & 2004 & 491 & 58.8 & 24 & - & 33.7 & 63.5 & 76.2 & 80 \\
\hline Kundu $^{23}$ & 2004 & 2737 & 61 & 65 & - & - & - & - & 93 \\
\hline Saranchuk $^{24}$ & 2005 & 647 & 58 & 15 & - & - & - & 87 & 93 \\
\hline Bianco $^{25}$ & 2005 & 1472 & 58 & 48 & - & - & - & 91 & 95 \\
\hline Penson $^{65}$ & 2005 & 1213 & $58 \%$ between $39-64$ & 60 & - & - & 44 & 69 & 74 \\
\hline $\mathrm{Sacco}^{27}$ & 2006 & 985 & 64.5 & 95.5 & - & 68 & 78 & 86.9 & 92.3 \\
\hline Eastham $^{32}$ & 2008 & 1577 & 58 & 60 & - & - & - & 79 & 94 \\
\hline Touijer $^{33}$ & 2008 & 222 & 59 & 23 & - & - & - & 75 & 82.8 \\
\hline Loeb $^{34}$ & 2008 & 3458 & 61 & $>18$ & - & - & - & - & 93 \\
\hline Krambeck $^{35}$ & 2009 & 496 & 61 & 12 & - & - & - & 93.7 & - \\
\hline Weighted means & & & 61.1 & & & 57.5 & 55.6 & 80 & 88.2 \\
\hline
\end{tabular}


Table 8. Laparoscopic Radical Prostatectomy: Urinary Continence Outcomes

\begin{tabular}{|c|c|c|c|c|c|c|c|c|c|}
\hline \multirow[b]{2}{*}{ Authors } & \multirow[b]{2}{*}{$\begin{array}{c}\text { Year of } \\
\text { publication }\end{array}$} & \multirow[b]{2}{*}{$\begin{array}{l}\text { Patients } \\
(N)\end{array}$} & \multirow[b]{2}{*}{$\begin{array}{c}\text { Mean/median age } \\
\text { (years) }\end{array}$} & \multirow[b]{2}{*}{$\begin{array}{l}\text { Follow-up } \\
\text { (months) }\end{array}$} & \multicolumn{5}{|c|}{$\%$ Urinary continence } \\
\hline & & & & & $\begin{array}{c}1 \\
\text { month }\end{array}$ & $\begin{array}{c}3 \\
\text { months }\end{array}$ & $\begin{array}{c}6 \\
\text { months }\end{array}$ & $\begin{array}{c}12 \\
\text { months }\end{array}$ & $\begin{array}{l}>18 \\
\text { months }\end{array}$ \\
\hline Guillonneau $^{62}$ & 2002 & 255 & - & 12 & - & - & - & 82.3 & - \\
\hline Rossweiler $^{38}$ & 2004 & 500 & 64 & 24 & 28 & 51 & 70 & 84 & 97 \\
\hline Rozet $^{40}$ & 2005 & 600 & 62 & 12 & - & - & - & 84 & - \\
\hline Stolzenburg $^{41}$ & 2005 & 700 & 63.4 & 12 & - & 73.8 & 83.8 & 92 & - \\
\hline Lein $^{42}$ & 2006 & 952 & 62 & 28.8 & - & - & - & - & 76 \\
\hline Rossweiler $^{46}$ & 2006 & 5824 & 64 & 12 & - & - & - & 84.9 & - \\
\hline Goeman ${ }^{45}$ & 2006 & 550 & 62.4 & 12 & 38 & 61.9 & 77 & 82.9 & 90.9 \\
\hline Curto $^{44}$ & 2006 & 425 & 62 & 12 & - & 76 & 95 & 95 & - \\
\hline Touijer $^{33}$ & 2008 & 193 & 60 & 23 & - & - & - & 48 & 62.1 \\
\hline Weighted means & - & - & 63.5 & - & 33.2 & 66 & 81.1 & 84.8 & 83.3 \\
\hline
\end{tabular}

compared with RRP. ${ }^{13,14}$ It is noteworthy to mention, however, that some transfusion rates reported in RRP series are significantly biased by autologous blood transfusion protocols, which have a clearly more liberal indication for transfusion during the procedure. ${ }^{33}$

The mean in-hospital stay was higher for LRP series than in RRP and RARP in our review $(4.87,3.48$, and 1.43 days, respectively). These results, however, probably reflected the differences in the location where the series were carried out. Most of the LRP series were conducted in Europe, where patients often stay in the hospital until the urinary catheter is removed; in the United States, the patients are usually discharged quickly from the hospital after surgery because of cultural disparities and differences in the insurance reimbursement patterns.

Surgical complications after RP have been documented in various previous series but few have used standardized classification systems. The absence of consensus within the surgical community on the best way to report complications has hampered accurate comparisons between different series and techniques. Lepor and coworkers, ${ }^{19}$ for example, reported a $6.5 \%$ overall incidence of complications in a series of 1000 RRPs performed by a single surgeon. In their series, however, blood transfusion $(9.7 \%)$ was not considered a complication. Most of the RARP series published include blood transfusion in their overall complication rates. Therefore, any direct comparison would be quite inaccurate.

Few studies that compare complications after large RRP, LRP, and RARP series are available in the literature. The results are conflicting. $\mathrm{Hu}$ and colleagues ${ }^{43}$ compared intraoperative and early postoperative complications of 358 consecutive LRPs with 322 RARPs and showed lower overall complication rates after RARP (27.7\% vs $14.6 \%)$. Instead, Rozet and associates, ${ }^{40}$ in a matched-pair analysis of 133 extraperitoneal RARPs and 133 extraperitoneal pure LRP, demonstrated a higher overall complication rate after RARP $(19.4 \%$ vs 9.1\%, $P=0.01)$. Most available series that compare RRP and RARP have reported similar complication rates between these two approaches. Krambeck and coworkers ${ }^{35}$ recently showed comparable overall perioperative complication rates between RARP and RRP (8.0\% vs $4.8 \%, P=0.064)$. Similarly, Nelson and colleagues ${ }^{28}$ showed equivalent rates of unscheduled visits $(\mathrm{RRP}=10 \%, \mathrm{RARP}=10 \%, P=0.95)$ and readmissions (RRP $=5 \%, \mathrm{RARP}=7 \%, P=0.12)$ because of postoperative complications between these two surgical approaches.

Ficarra and associates ${ }^{13}$ showed in a cumulative analysis of comparative reports that the overall complication rate is significantly higher in those patients who are undergoing RRP. The same report showed that the complication rates after RARP or LRP are similar. In our review, the weighted

Table 9. Robot-Assisted Radical Prostatectomy: Continence Outcomes

\begin{tabular}{|c|c|c|c|c|c|c|c|c|c|}
\hline \multirow[b]{2}{*}{ Authors } & \multirow[b]{2}{*}{$\begin{array}{l}\text { Year of } \\
\text { Publication }\end{array}$} & \multirow[b]{2}{*}{$\begin{array}{l}\text { Patients } \\
(N)\end{array}$} & \multirow[b]{2}{*}{$\begin{array}{c}\text { Median/mean age } \\
\text { (years) }\end{array}$} & \multirow[b]{2}{*}{$\begin{array}{l}\text { Follow-up } \\
\text { (months) }\end{array}$} & \multicolumn{5}{|c|}{$\%$ Urinary continence } \\
\hline & & & & & Immediate & $\begin{array}{c}1 \\
\text { month }\end{array}$ & $\begin{array}{c}3 \\
\text { months }\end{array}$ & $\begin{array}{c}6 \\
\text { months }\end{array}$ & $\begin{array}{c}12 \\
\text { months }\end{array}$ \\
\hline Joseph $^{48}$ & 2006 & 325 & 60 & 6 & 24 & 56 & 93 & 96 & - \\
\hline Menon $^{63}$ & 2007 & 1142 & 60.2 & 12 & - & - & - & - & 92.00 \\
\hline Borin $^{50}$ & 2007 & 400 & 61.2 & 6 & - & 70.5 & 89 & 97 & - \\
\hline Zorn $^{51}$ & 2007 & 300 & 59.4 & 24 & - & 23.00 & 47.00 & 68.00 & 90.00 \\
\hline Patel $^{64}$ & 2007 & 500 & 63.2 & 12 & 27 & - & 89 & 95 & 97 \\
\hline \multirow[t]{3}{*}{ Tewari $^{58}$} & 2008 & 214 (NR) & 64.3 & 13 & 13.1 & 35.2 & 50.2 & 61.9 & 82.1 \\
\hline & & 304 (AR) & 62.8 & 13 & 27 & 59 & 76.6 & 85.6 & 91.2 \\
\hline & & 182 (TR) & 61.2 & 6 & 38.4 & 82.5 & 91.3 & 97.1 & - \\
\hline Murphy $^{53}$ & 2009 & 395 & 60.2 & $>18$ & - & - & - & - & 91.40 \\
\hline Krambeck $^{35}$ & 2009 & 294 & 61 & 12 & - & - & - & - & 91.8 \\
\hline Weighted means & & & 61.1 & & 25.7 & 54.3 & 78.6 & 87.5 & 92 \\
\hline
\end{tabular}

$\mathrm{NR}=$ no reconstruction; $\mathrm{AR}=$ anterior reconstruction; $\mathrm{TR}=$ total reconstruction . 

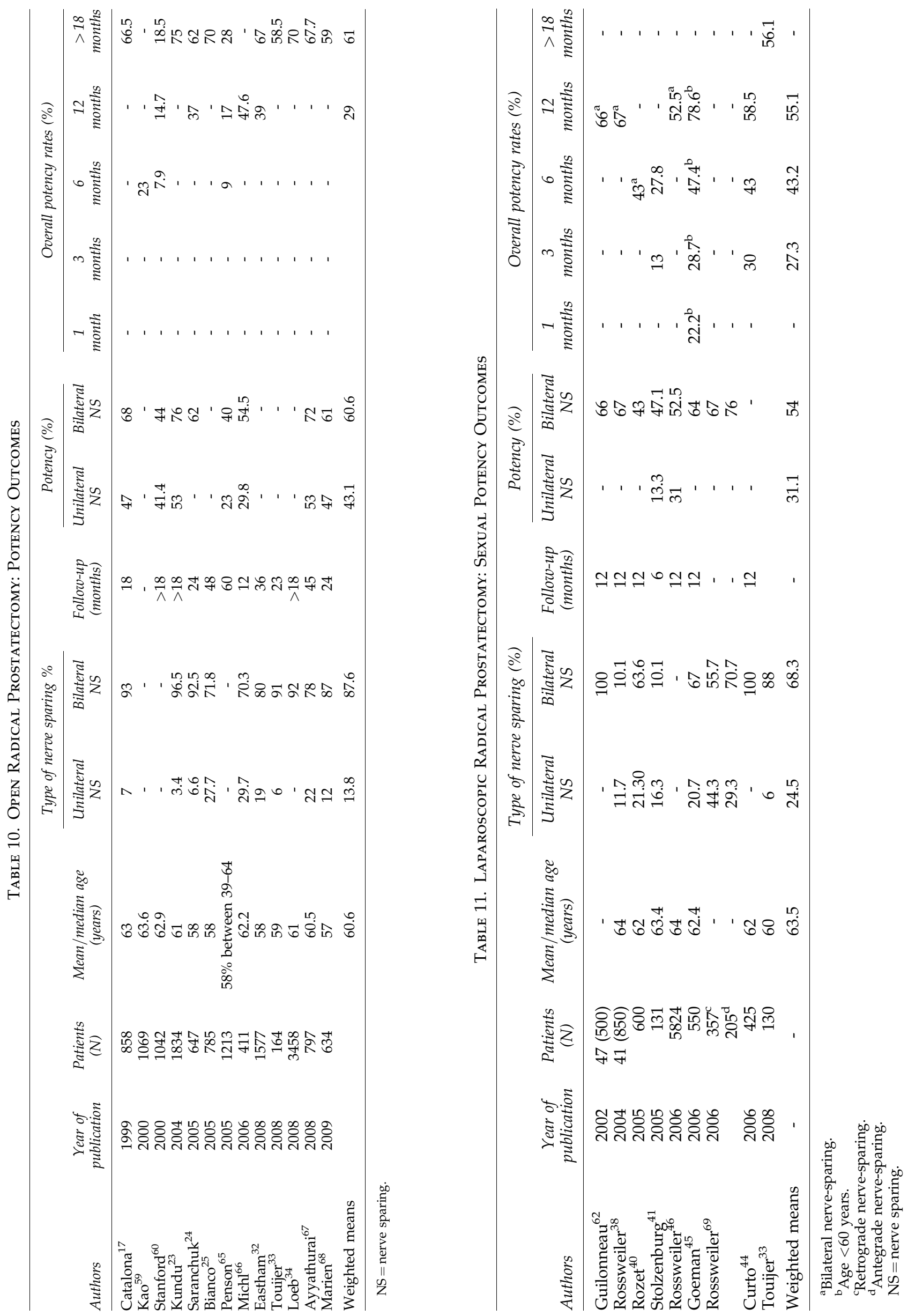


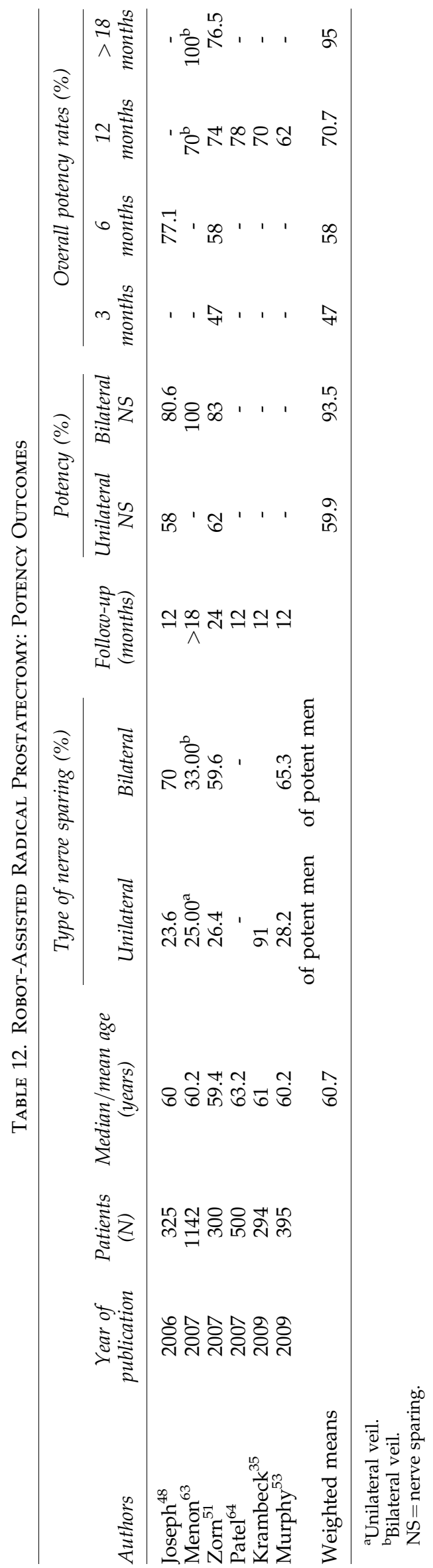

mean postoperative complication rates were similar between the three approaches $(10.3 \%, 10.98 \%$, and $10.3 \%$, respectively).

\section{Oncologic outcomes}

PSM after RP is thought to be an independent predictive factor of biochemical recurrence, local recurrence, and development of distant metastasis. ${ }^{72}$ In the absence of long-term data that compare biochemical recurrence and disease-free survival between the different surgical approaches, data regarding PSM are most helpful as a surrogate for these outcomes. Few studies that compare PSM rates after RRP, LRP, and RARP are available, with conflicting results.

Parsons and Bennett ${ }^{14}$ evaluated the surgical margin status in 13 comparative studies and showed no significant differences in overall risk or incidence of PSM between RRP and LRP or RARP. Of note, in the subgroup analysis by tumor stage, there were no significant differences between the groups for $T_{2}$ cancers or $T_{3}$ cancers. Likewise, Schroek and colleagues, ${ }^{30}$ comparing 362 consecutive RARPs with 435 RRPs, found no significant difference in PSM rates between RARP and RRP. The risk of PSA recurrence was also not significantly different after adjusting for clinical (hazard ratio $0.82,95 \%$ confidence interval [CI] $0.48-1.38 ; P=0.448)$ and pathologic differences $(0.94,0.55-1.61 ; P=0.824)$. Similarly, Krambeck and coworkers ${ }^{35}$ showed, in their matched-pair analysis, no difference in the PSM rates between RARP and RRP. The 3-year biochemical disease-free survival was also not significantly different.

Contrary to these results, Ficarra and associates, ${ }^{13}$ evaluating PSM rates in six studies that compared RARP and RRP, suggested a significant advantage in the population who underwent RARP (relative risk [RR]: 1.58 ; 95\% CI of RR: $1.29-$ 1.94; $P<0.00001$ ). When analyzing the PSM rates in patients with organ-confined prostate cancer, RARP was associated with the lowest risk of PSMs (RR: 2.23; 95\% CI of RR: 1.363.67; $P=0.002)$. The PSM rates observed after open RP and LRP were similar. Our analysis that included high-volume centers confirmed this trend to lower PSM rates after RARP compared with RRP and LRP, because this surgical approach revealed a weighted mean overall PSM rate of $13.6 \%$, whereas LRP and RRP yielded a PSM rate of $21.3 \%$ and $24 \%$, respectively. PSM rates for $\mathrm{pT}_{2}$ tumors were also lowest among RARP series $(16.8 \%$ for RRP; $12.4 \%$ for LRP, and $9.6 \%$ for RARP). Randomized trials are necessary, however, before establishing definitive conclusions.

\section{Urinary continence outcomes}

Objective evaluation of continence outcomes after RP remains stalled by the lack of standardization among series. Most studies used no validated institutional questionnaires, and the outcomes were assessed by an open interview.

Very few data regarding continence are available in the studies that compared RARP with LRP or with RRP, and meaningful conclusions as to whether any particular approach delivers superior continence outcomes are impractical. Nevertheless, better continence rates were suggested after RARP in some previous studies. Tewari and coworkers ${ }^{73}$ showed, in a nonrandomized comparative study, that RARP provides earlier continence recovery compared with RRP. These authors reported a prospective comparison between 100 RRPs and 200 
RARPs and demonstrated a shorter time to return of continence after RARP (median time 160 vs 44 days; $P<0.05$ ).

Contrarily to these results, Krambeck and associates ${ }^{35}$ in a matched comparison of RRP and RARP, showed comparable continence rates at the 1-year follow-up (RARP 91.8\%, RRP 93.7\%, $P=0.344$ ). Likewise Parsons and Bennett ${ }^{14}$ evaluated urinary continence at 1 year of follow-up in four comparative studies. There was no significant difference in urinary continence between LRP or RARP and RRP.

Ficarra and coworkers ${ }^{13}$ analyzed eight articles that provided data on urinary continence recovery after RRP or LRP. Considering the studies that evaluated the learning curve of LRP, the return of continence was better after RRP. The cumulative analysis suggested similar continence rates after RRP or LRP, however. The cumulative analysis that compared RARP with RRP was not possible because of the heterogeneity of the studies. ${ }^{13}$

In our review, the weighted mean continence rates at 12 months for RRP, LRP, and RARP were $80 \%, 84.8 \%$, and $92 \%$, respectively. Our data support the statement that the continence rates after RRP and LRP are similar. The RARP continence rates were higher in our study when compared with RRP and LRP. Randomized prospective studies are necessary, however, to accurately compare the continence rates between the three surgical approaches.

\section{Potency outcomes}

Potency is one of the most difficult outcomes to compare after RP. Factors other than the surgeon or the approach have a significant effect on recovery of potency, including patient age, type and quality of the nerve sparing, and use of medications. Also, the assessment of postoperative continence is not standardized, including nonvalidated questionnaires and open interviews.

Whether there is a difference in the potency rates after RRP, LRP, or RARP is still not clear. It has been proposed that RARP may prevent damage to the neurovascular bundle because the three-dimensional magnified vision offered by the Da Vinci Surgical System allows more precise dissection and prevents inadvertent incision, traction, or incorporation of the neurovascular bundle into the suture or clip. Tewari and colleagues $^{73}$ demonstrated better and earlier potency recovery after RARP compared with RRP. Patients who underwent RARPs showed earlier return of erections $(50 \%$ at a mean follow-up of 180 days $v s 50 \%$ at a mean of 440 days after RRP) as well as a quicker return to intercourse (50\% at 340 days vs $50 \%$ at 700 days for RRP) compared with RRP patients. Contrary to these results, the matched-pair analysis conducted by Krambeck and coworkers ${ }^{35}$ showed comparable potency rates between RARP and RRP at 1-year follow-up. (RARP 70.0\%, RRP 62.8\%, $P=0.081$ ).

Regarding the comparison between RARP and LRP, Joseph and associates ${ }^{74}$ conducted a single retrospective study that compared noncontemporary series of patients who were evaluated for erectile function recovery after LRP and RARP. At 3 months after surgery, only a nonstatistically significant trend in favor of RARP was observed. In our review, the weighted mean potency rates for bilateral nerve sparing were higher for RARP compared with the other two surgical approaches (93\% vs $60.6 \%$ for RRP vs $54 \%$ for LRP). The poor methodology of the published studies and the absence of randomized clinical trials prevent any definitive conclusions, however.

Our study has some limitations. Although we included only high-volume centers in our analysis, several centers have multiple surgeons who perform RARP and LRP. Therefore, the individual learning curve of each surgeon could have been a source of bias. In addition, the series analyzed in each group are not contemporary. The outcomes from the RRP series are based on less contemporary patient cohorts. Therefore, some of the patients in the open RRP series were operated on before widespread use of PSA screening; baseline patient characteristics were not consistently comparable-ie, the pathologic stage was more advanced in the RRP series compared with the RARP series. Finally, comparison of outcomes using weighted means has some inherent limitations; a single large series with suboptimal outcomes can determine a worse weighted mean even if excellent results are reported in several smaller series.

\section{Conclusions}

Our analysis of large RRP, LRP, and RARP series with a sample size of 250 or more patients has led to the following conclusions:

- RRP, LRP, and RARP that are performed in highvolume centers are safe options for treatment of patients with localized prostate cancer, presenting similar overall complication rates.

- LRP and RARP are associated with decreased operative blood loss and decreased risk of transfusion when compared with RRP.

- Our analysis including high-volume centers showed lower weighted mean PSM rates and higher continence and potency rates after RARP compared with RRP and LRP. The lack of randomized trials and long-term follow-up studies that compare the three approaches, however, precludes definitive conclusions.

\section{Disclosure Statement}

No competing financial interests exist.

\section{References}

1. Meng MV, Elkin EP, Harlan SR, et al. Predictors of treatment after initial surveillance in men with prostate cancer: Results from CaPSURE. J Urol 2003;170:2279-2283.

2. Altekruse SF, Kosary CL, Krapcho M, et al, eds. SEER Cancer Statistics Review, 1975-2007. National Cancer Institute, Bethesda, Md. http://seer.cancer.gov/csr/1975_2007/, based on November 2009 SEER data submission, posted to the SEER web site, 2010.

3. Walsh PC, Donker PJ. Impotence following radical prostatectomy: Insight into etiology and prevention. J Urol 1982; 128:492-497.

4. Bill-Axelson A, Holmberg L, Ruutu M, et al. Radical prostatectomy versus watchful waiting in early prostate cancer. N Engl J Med 2005;352:1977-1984.

5. Reiner WG, Walsh PC. An anatomical approach to the surgical management of the dorsal vein and Santorini's plexus during radical retropubic surgery. J Urol 1979;121:198-200.

6. Oelrich TM. The urethral sphincter muscle in the male. Am J Anat 1980;158:229-246. 
7. Schuessler WW, Schulam PG, Clayman RV, Kavoussi LR. Laparoscopic radical prostatectomy: Initial short-term experience. Urology 1997;50:854-857.

8. Guillonneau B, Vallancien G. Laparoscopic radical prostatectomy: The Montsouris experience. J Urol 2000;163:418-422.

9. Rassweiler J, Sentker L, Seemann O, et al. Laparoscopic radical prostatectomy with the Heilbronn technique: An analysis of the first 180 cases. J Urol 2001;166:2101-2108.

10. Eden CG, Cahill D, Vass JA, et al. Laparoscopic radical prostatectomy: The initial UK series. BJU Int 2002;90:876-882.

11. Binder J, Kramer W. Robotically-assisted laparoscopic radical prostatectomy. BJU Int 2001;87:408-410.

12. Pasticier G, Rietbergen JB, Guillonneau B, et al. Robotically assisted laparoscopic radical prostatectomy: Feasibility study in men. Eur Urol 2001;40:70-74.

13. Ficarra V, Novara G, Artibani W, et al. Retropubic, laparoscopic, and robot-assisted radical prostatectomy: A systematic review and cumulative analysis of comparative studies. Eur Urol 2009;55:1037-1063.

14. Parsons JK, Bennett JL. Outcomes of retropubic, laparoscopic, and robotic-assisted prostatectomy. Urology 2008;72: 412-416.

15. Berryhill R Jr, Jhaveri J, Yadav R, et al. Robotic prostatectomy: A review of outcomes compared with laparoscopic and open approaches. Urology 2008;72:15-23.

16. Zincke H, Bergstralh EJ, Blute ML, et al. Radical prostatectomy for clinically localized prostate cancer: Long-term results of 1,143 patients from a single institution. J Clin Oncol 1994;12:2254-2263.

17. Catalona WJ, Carvalhal GF, Mager DE, Smith DS. Potency, continence and complication rates in 1,870 consecutive radical retropubic prostatectomies. J Urol 1999;162:433-438.

18. Grossfeld GD, Chang JJ, Broering JM, et al. Impact of positive surgical margins on prostate cancer recurrence and the use of secondary cancer treatment: Data from the CaPSURE database. J Urol 2000;163:1171-1177.

19. Lepor H, Nieder AM, Ferrandino MN. Intraoperative and postoperative complications of radical retropubic prostatectomy in a consecutive series of 1,000 cases. J Urol 2001;166: 1729-1733.

20. Hull GW, Rabbani F, Abbas F, et al. Cancer control with radical prostatectomy alone in 1,000 consecutive patients. J Urol 2002;167:528-534.

21. Augustin $H$, Hammerer $P$, Graefen $M$, et al. Intraoperative and perioperative morbidity of contemporary radical retropubic prostatectomy in a consecutive series of 1243 patients: Results of a single center between 1999 and 2002. Eur Urol 2003;43:113-118.

22. Han M, Partin AW, Chan DY, et al. An evaluation of the decreasing incidence of positive surgical margins in a large retropubic prostatectomy series. J Urol 2004;171:23-26.

23. Kundu SD, Roehl KA, Eggener SE, et al. Potency, continence and complications in 3,477 consecutive radical retropubic prostatectomies. J Urol 2004;172:2227-2231.

24. Saranchuk JW, Kattan MW, Elkin E, et al. Achieving optimal outcomes after radical prostatectomy. J Clin Oncol 2005;23: 4146-4151.

25. Bianco Jr FJ, Scardino PT, Eastham JA. Radical prostatectomy: Long-term cancer control and recovery of sexual and urinary function ("trifecta"). Urology 2005;66(suppl 5):83-94.

26. Orvieto MA, Alsikafi NF, Shalhav AL, et al. Impact of surgical margin status on long-term cancer control after radical prostatectomy. BJU Int 2006;98:1199-1203.
27. Sacco E, Prayer-Galetti T, Pinto F, et al. Urinary incontinence after radical prostatectomy: Incidence by definition, risk factors and temporal trend in a large series with a long-term follow-up. BJU Int 2006;97:1234-1241.

28. Nelson B, Kaufman M, Broughton G, et al. Comparison of length of hospital stay between radical retropubic prostatectomy and robotic assisted laparoscopic prostatectomy. J Urol 2007;177:929-931.

29. Sengupta S, Blute ML, Bagniewski SM, et al. After radical retropubic prostatectomy 'insignificant' prostate cancer has a risk of progression similar to low-risk 'significant' cancer. BJU Int 2008;101:170-174.

30. Schroeck FR, Sun L, Freedland SJ, et al. Comparison of prostate-specific antigen recurrence-free survival in a contemporary cohort of patients undergoing either radical retropubic or robot-assisted laparoscopic radical prostatectomy. BJU Int 2008;102:28-32.

31. Chan RC, Barocas DA, Chang SS, et al. Effect of a large prostate gland on open and robotically assisted laparoscopic radical prostatectomy. BJU Int 2008;101:1140-1144.

32. Eastham JA, Scardino PT, Kattan MW. Predicting an optimal outcome after radical prostatectomy: The trifecta nomogram. J Urol 2008;179:2207-2211.

33. Touijer K, Eastham JA, Secin FP, et al. Comprehensive prospective comparative analysis of outcomes between open and laparoscopic radical prostatectomy conducted in 2003 to 2005. J Urol 2008;179:1811-1817.

34. Loeb S, Roehl KA, Helfand BT, Catalona WJ. Complications of open radical retropubic prostatectomy in potential candidates for active monitoring. Urology 2008;72:887-891.

35. Krambeck AE, DiMarco DS, Rangel LJ, et al. Radical prostatectomy for prostatic adenocarcinoma: A matched comparison of open retropubic and robot-assisted techniques. BJU Int 2009;103:448-453.

36. Constantinides CA, Tyritzis SI, Skolarikos A, et al. Shortand long-term complications of open radical prostatectomy according to the Clavien classification system. BJU Int 2009; 103:336-340.

37. Guillonneau B, el-Fettouh $\mathrm{H}$, Baumert $\mathrm{H}$, et al. Laparoscopic radical prostatectomy: oncological evaluation after 1,000 cases a Montsouris Institute. J Urol 2003;169:1261-1266.

38. Rassweiler J, Schulze M, Teber D, et al. Laparoscopic radical prostatectomy: Functional and oncological outcomes. Curr Opin Urol 2004;14:75-82.

39. Gonzalgo ML, Pavlovich CP, Trock BJ, et al. Classification and trends of perioperative morbidities following laparoscopic radical prostatectomy. J Urol 2005;174:135-139.

40. Rozet F, Galiano M, Cathelineau X, et al. Extraperitoneal laparoscopic radical prostatectomy: A prospective evaluation of 600 cases. J Urol 2005;174:908-911.

41. Stolzenburg JU, Rabenalt R, DO M, et al. Endoscopic extraperitoneal radical prostatectomy: Oncological and functional results after 700 procedures. J Urol 2005;174:1271-1275.

42. Lein M, Stibane I, Mansour R, et al. Complications, urinary continence, and oncologic outcome of 1000 laparoscopic transperitoneal radical prostatectomies-experience at the Charité Hospital Berlin, Campus Mitte. Eur Urol 2006;50:1278-1284.

43. Hu JC, Nelson RA, Wilson TG, et al. Perioperative complications of laparoscopic and robotic assisted laparoscopic radical prostatectomy. J Urol 2006;175:541-546.

44. Curto F, Benijts J, Pansadoro A, et al. Nerve sparing laparoscopic radical prostatectomy: Our technique. Eur Urol 2006;49:344-352. 
45. Goeman L, Salomon L, La De Taille A, et al. Long-term functional and oncological results after retroperitoneal laparoscopic prostatectomy according to a prospective evaluation of 550 patients. World J Urol 2006;24:281-288.

46. Rassweiler J, Stolzenburg J, Sulser T, et al. Laparoscopic radical prostatectomy-the experience of the German Laparoscopic Working Group. Eur Urol 2006;49:113-119.

47. Pavlovich CP, Trock BJ, Sulman A, et al. 3-year actuarial biochemical recurrence-free survival following laparoscopic radical prostatectomy: experience from a tertiary referral center in the United States. J Urol 2008;179:917-922.

48. Joseph JV, Rosenbaum R, Madeb R, et al. Robotic extraperitoneal radical prostatectomy: An alternative approach. J Urol 2006;175:945-951.

49. Badani KK, Kaul S, Menon M. Evolution of robotic radical prostatectomy: Assessment after 2766 procedures. Cancer 2007;110:1951-1958.

50. Borin JF, Skarecky DW, Narula N, Ahlering TE. Impact of urethral stump length on continence and positive surgical margins in robot-assisted laparoscopic prostatectomy. Urology 2007;70:173-178.

51. Zorn KC, Gofrit ON, Orvieto MA, et al. Robotic-assisted laparoscopic prostatectomy: functional and pathologic outcomes with interfascial nerve preservation. Eur Urol 2007;51: 755-763.

52. Patel VR, Palmer KJ, Coughlin G, Samavedi S. Robotassisted laparoscopic radical prostatectomy: Perioperative outcomes of 1500 cases. J Endourol 2008;22:2299-2305.

53. Murphy DG, Kerger M, Crowe H, et al. Operative details and oncological and functional outcome of robotic-assisted laparoscopic radical prostatectomy: 400 cases with a minimum of 12 months follow-up. Eur Urol 2009;55:1358-1366.

54. Ham WS, Park SY, Rha KH, et al. Robotic radical prostatectomy for patients with locally advanced prostate cancer is feasible: Results of a single-institution study. J Laparoendosc Adv Surg Tech A 2009;19:329-332.

55. Ward JF, Zincke H, Bergstralh EJ, et al. The impact of surgical approach (nerve bundle preservation versus wide local excision) on surgical margins and biochemical recurrence following radical prostatectomy. J Urol 2004;172:1328-1332.

56. Porter CR, Kodama K, Gibbons RP, et al. 25-year prostate cancer control and survival outcomes: A 40-year radical prostatectomy single institution series. J Urol 2006;176:569574 .

57. Chun FK, Graefen M, Zacharias M, et al. Anatomic radical retropubic prostatectomy-long-term recurrence-free survival rates for localized prostate cancer. World J Urol 2006;24:273280.

58. Tewari A, Jhaveri J, Rao S, et al. Total reconstruction of the vesico-urethral junction. BJU Int 2008;101:871-877.

59. Kao TC, Cruess DF, Garner D, et al. Multicenter patient selfreporting questionnaire on impotence, incontinence and stricture after radical prostatectomy. J Urol 2000;163:858864.

60. Stanford JL, Feng Z, Hamilton AS, et al. Urinary and sexual function after radical prostatectomy for clinically localized prostate cancer: the Prostate Cancer Outcomes Study. JAMA 2000;283:354-360.

61. Lepor H, Kaci L. The impact of open radical retropubic prostatectomy on continence and lower urinary tract symptoms: A prospective assessment using validated self-administered outcome instruments. J Urol 2004;171:1216-1219.
62. Guillonneau B, Cathelineau X, Doublet JD, et al. Laparoscopic radical prostatectomy: Assessment after 550 procedures. Crit Rev Oncol Hematol 2002;43:123-133.

63. Menon M, Shrivastava A, Kaul S, et al. Vattikuti Institute prostatectomy: Contemporary technique and analysis of results. Eur Urol 2007;51:648-657.

64. Patel VR, Thaly R, Shah K. Robotic radical prostatectomy: Outcomes of 500 cases. BJU Int 2007;99:1109-1112.

65. Penson DF, McLerran D, Feng Z, et al. 5-year urinary and sexual outcomes after radical prostatectomy: results from the prostate cancer outcomes study. J Urol 2005;173:1701-1705.

66. Michl UH, Friedrich MG, Graefen M, et al. Prediction of postoperative sexual function after nerve sparing radical retropubic prostatectomy. J Urol 2006;176:227-231.

67. Ayyathurai R, Manoharan M, Nieder AM, et al. Factors affecting erectile function after radical retropubic prostatectomy: Results from 1620 consecutive patients. BJU Int 2008; 101:833-836.

68. Marien T, Sankin A, Lepor H. Factors predicting preservation of erectile function in men undergoing open radical retropubic prostatectomy. J Urol 2009;181:1817-1822.

69. Rassweiler J, Wagner AA, Moazin M, et al. Anatomic nervesparing laparoscopic radical prostatectomy: Comparison of retrograde and antegrade techniques. Urology 2006;68:587592.

70. Nelson JB. Debate: Open radical prostatectomy vs. laparoscopic vs. robotic. Urol Oncol 2007;25:490-493.

71. Fracalanza S, Ficarra V, Cavalleri S, et al. Is robotically assisted laparoscopic radical prostatectomy less invasive than retropubic radical prostatectomy? Results from a prospective, unrandomized, comparative study. BJU Int 2008;101: 1145-1149.

72. Pfitzenmaier J, Pahernik S, Tremmel T, et al. Positive surgical margins after radical prostatectomy: Do they have an impact on biochemical or clinical progression? BJU Int 2008;102:1413-1418.

73. Tewari A, Srivasatava A, Menon M; Members of the VIP Team. A prospective comparison of radical retropubic and robot-assisted prostatectomy: Experience in one institution. BJU Int 2003;92:205-210.

74. Joseph JV, Vicente I, Madeb R, et al. Robot-assisted vs pure laparoscopic radical prostatectomy: Are there any differences? BJU Int 2005;96:39-42.

Address correspondence to: Rafael F. Coelho, M.D. 410 Celebration Place, Suite 200 Celebration, FL 34747

E-mail: rafael.coelho.md@flhosp.org

$$
\begin{aligned}
& \text { Abbreviations Used } \\
& \mathrm{CI}= \text { confidence interval } \\
& \mathrm{EBL}= \text { estimated blood loss } \\
& \mathrm{LRP}= \text { laparoscopic radical prostatectomy } \\
& \mathrm{PSA}= \text { prostate-specific antigen } \\
& \mathrm{PSM}=\text { positive surgical margin } \\
& \mathrm{RARP}=\text { robot-assisted radical prostatectomy } \\
& \mathrm{RP}=\text { radical prostatectomy } \\
& \mathrm{RR}=\text { relative risk } \\
& \mathrm{RRP}=\text { retropubic radical prostatectomy }
\end{aligned}
$$


